\title{
Monoamine depletion by reuptake inhibitors
}

Marty Hinz'

Alvin Stein ${ }^{2}$

Thomas Uncini ${ }^{3}$

'Clinical Research, NeuroResearch

Clinics Inc, Cape Coral, FL;

${ }^{2}$ Stein Orthopedic Associates,

Plantation, FL; ${ }^{3}$ DBS Labs Inc, Duluth, MN, USA
Correspondence: Marty Hinz 1008 Dolphin Dr, Cape Coral, FL 33904, USA

Tel +I 2186262220

Fax + I 2186261638

Email marty@hinzmd.com
This article was published in the following Dove Press journal:

Drug, Healthcare and Patient Safety

19 October 2011

Number of times this article has been viewed

Background: Disagreement exists regarding the etiology of cessation of the observed clinical results with administration of reuptake inhibitors. Traditionally, when drug effects wane, it is known as tachyphylaxis. With reuptake inhibitors, the placebo effect is significantly greater than the drug effect in the treatment of depression and attention deficit hyperactivity disorder, leading some to assert that waning of drug effects is placebo relapse, not tachyphylaxis.

Methods: Two groups were retrospectively evaluated. Group 1 was composed of subjects with depression and Group 2 was composed of bariatric subjects treated with reuptake inhibitors for appetite suppression.

Results: In Group 1, 200 subjects with depression were treated with citalopram $20 \mathrm{mg}$ per day. A total of $46.5 \%(n=93)$ achieved relief of symptoms (Hamilton-D rating score $\leq 7), 37$ $(39.8 \%)$ of whom experienced recurrence of depression symptoms, at which point an amino acid precursor formula was started. Within 1-5 days, 97.3\% $(n=36)$ experienced relief of depression symptoms. In Group 2, 220 subjects were treated with phentermine $30 \mathrm{mg}$ in the morning and citalopram $20 \mathrm{mg}$ at $4 \mathrm{pm}$. In this group, $90.0 \%(\mathrm{n}=198)$ achieved adequate appetite suppression. The appetite suppression ceased in all 198 subjects within 4-48 days. Administration of an amino acid precursor formula restored appetite suppression in $98.5 \%$ ( $\mathrm{n}=195$ ) of subjects within $1-5$ days.

Conclusion: Reuptake inhibitors do not increase the total number of monoamine molecules in the central nervous system. Their mechanism of action facilitates redistribution of monoamines from one place to another. In the process, conditions are induced that facilitate depletion of monoamines. The "reuptake inhibitor monoamine depletion theory" of this paper offers a novel and unified explanation for the waning of response seen after a reuptake inhibitor is started, independent of a drug or placebo etiology.

Keywords: reuptake inhibitor, depletion, tachyphylaxis, relapse, serotonin, dopamine

\section{Introduction}

Tricyclic antidepressants, nonspecific reuptake inhibitors, became available in $1956 .{ }^{1}$ They dominated depression treatment until the first selective serotonin reuptake inhibitor (SSRI), fluoxetine, became available in $1988 .{ }^{1}$ The sympathomimetic anorectics, including phentermine, diethylproprion, and phendimetrazine, induce weight loss through appetite suppression. Their mechanism of action is thought to include norepinephrine reuptake inhibition. ${ }^{2}$ As with the rest of the reuptake inhibitors, the mechanism of action of amphetamines is unknown. However, it is thought to be due to dopamine and norepinephrine reuptake inhibition, which induces appetite suppression. Amphetamines are also used in attention deficit hyperactivity disorder (ADHD). ${ }^{3}$ These classes of 
reuptake inhibitors are also approved for other applications. Fluvoxamine, an SSRI, is approved only for the treatment of obsessive-compulsive disorder and social anxiety syndrome. ${ }^{4}$ Bupropion hydrochloride, a dopamine and norepinephrine reuptake inhibitor, is indicated for smoking discontinuation. ${ }^{5}$

Reuptake inhibitors share the property of tolerance, that is waning of the drug's effects. In other classes of drugs this effect is known as tachyphylaxis. Tachyphylaxis is formally defined as a "diminished response to later increments in a sequence of applications of a physiologically active substance" (ie, the drug stops working and its clinical effects are no longer observed). The concept of reuptake inhibitor tachyphylaxis is controversial. Double-blind, placebo-controlled studies reveal that in depression and ADHD treatment, the placebo response is greater than the drug effect in relief of symptoms. ${ }^{7,8}$ This leads to the argument that discontinuation of a drug's clinical effects predominantly represents a placebo relapse rather than drug tachyphylaxis., ${ }^{9,10}$

This paper presents the novel reuptake inhibitor monoamine depletion theory, which explains why symptoms that are controlled at the start of treatment return, irrespective of the cause of initial relief (placebo relapse or drug tachyphylaxis). Under this novel theory, a relative nutritional deficiency occurs, a situation that can only be managed with administration of proper levels of nutrients.

The following scientific facts exist. The monoamines serotonin, dopamine, norepinephrine, and epinephrine - do not cross the blood-brain barrier. There are a finite number of monoamine neurotransmitter molecules in the central nervous system (CNS). Reuptake inhibitor drugs do not increase the total number of these centrally acting monoamine molecules in the CNS. The only way to increase the total number of monoamine molecules in this finite CNS universe is through a nutritional approach with administration of properly balanced serotonin and dopamine amino acid precursors. These precursors cross the blood-brain barrier and are synthesized in the CNS into new monoamine molecules. ${ }^{8,9,11-16}$

\section{Methods and materials}

Serotonin, dopamine, norepinephrine, and epinephrine are herein referred to as "monoamines". A comprehensive search of the literature was performed, specifically focusing on depletion of monoamines by reuptake inhibitors, reuptake inhibitor tachyphylaxis, and placebo relapse of depression and ADHD symptoms.

Two pilot study groups were identified. Group 1 was composed of 200 subjects taking the SSRI citalopram for depression, which was screened initially with the Diagnostic and Statistical Manual of Mental Disorders, Fourth Edition (DSM-IV) criteria $^{17}$, then tracked with the Hamilton-D rating scale for depression. The number of Group 1 subjects who initially achieved relief of depression symptoms (Hamilton-D $\leq 7)$ was $n=93$. Subjects who did not initially achieve relief of depression symptoms on $20 \mathrm{mg}$ of citalopram each morning (Hamilton-D > 7) were excluded from the study. The next criterion for inclusion was the return of depression symptoms $(n=37)$ while taking the prescribed reuptake inhibitor drug.

Group 2 was composed of 220 patients taking a combination of citalopram and phentermine for appetite suppression during bariatric treatment (see Table 2). Since tools do not exist for evaluating drug-induced appetite suppression, the following novel questions were used; a positive answer to any question indicated inadequate appetite suppression. "Since your last office visit have you: been inappropriately snacking on food, been inappropriately nibbling on food, eaten more than your calorie prescription, or needed to use willpower to stay away from food in order to keep on your diet?" The number of Group 2 subjects who achieved initial control of appetite was $n=$ 198. Subjects who did not initially achieve adequate appetite control were excluded from the study. The next criterion for inclusion was the loss of appetite suppression $(\mathrm{n}=198)$ while taking the prescribed reuptake inhibitor drugs.

Subjects were instructed to immediately report the return of depression symptoms or loss of appetite control. Subjects were then continued on the $\operatorname{drug}(\mathrm{s})$ and started on monoamine amino acid precursors and cofactors in divided doses at the following daily dosing values: L-cysteine $4500 \mathrm{mg}$, L-tyrosine $3000 \mathrm{mg}$, vitamin C $1000 \mathrm{mg}$, L-lysine $500 \mathrm{mg}$, 5-hydroxytryptophan (5-HTP) $300 \mathrm{mg}$, calcium citrate $220 \mathrm{mg}$, vitamin B6 $75 \mathrm{mg}$, folate $400 \mu \mathrm{g}$, and selenium $400 \mu \mathrm{g}$.

A full discussion of the scientific basis for each of these amino acid and cofactor nutrients is covered in the authors' previous writings. ${ }^{8,9,11-16,20-22} \mathrm{~A}$ brief overview is as follows. L-tyrosine and 5-HTP are dopamine and serotonin precursors, respectively. Vitamin C, vitamin B6, and calcium citrate are cofactors required in the synthesis of serotonin and/or dopamine. L-cysteine is administered to compensate for L-tyrosine-induced depletion of sulfur amino acids. Folate is required for optimal sulfur amino acid synthesis. Selenium is given in response to cysteine's ability to concentrate methylmercury in the CNS. L-lysine prevents loose hair follicles during bariatric treatment.

\section{Results}

\section{Group I: depression}

A group of 200 patients who were positively diagnosed with depression on DSM-IV depression criteria screening and had 
a Hamilton-D depression score $>7$ (see row 1, Table 1) were identified. All were started on citalopram $20 \mathrm{mg}$ per day in the morning. Two weeks after the initiation of treatment with citalopram $20 \mathrm{mg}$, 93 subjects were diagnosed with remission of depression (Hamilton-D $\leq 7$; row 2, Table 1). The remission group continued citalopram $20 \mathrm{mg}$ each morning. All were instructed to immediately report if depression returned. They were then followed in clinic every 2-4 weeks. In the 18 months after symptom control had been achieved, 37 subjects experienced return of depression (Hamilton-D $>7$; row 3, Table 1). They were re-evaluated using the Hamilton-D depression scale within 14 days of return of symptoms then started on the amino acid formula discussed in the Materials and methods section. On this amino acid formula, 36 of the 37 subjects reported relief of symptoms, with a mean time of 1.9 days and a range of 1 to 5 days (see Tables 3 and 4). Follow-up 6 months later revealed no return of depression symptoms in those subjects taking the amino acid formula.

\section{Group 2: appetite suppression}

Group 2, comprising 220 subjects, was started on $15 \mathrm{mg}$ of phentermine in the morning with $20 \mathrm{mg}$ of citalopram at 4 pm for control of appetite in a bariatric medicine program.

One week later, independent of the appetite control in place, all were increased to $30 \mathrm{mg}$ of phentermine in the morning with $20 \mathrm{mg}$ of citalopram at $4 \mathrm{pm}$. One week later, $198 \mathrm{sub}-$ jects were found to have adequate appetite suppression and were then followed with weekly visits to monitor appetite suppression. Novel questioning (as covered in the Methods and materials section) revealed inadequate appetite control in all subjects within 4-48 days, at which point the drugs were continued and the amino acid formula outlined in the Methods and materials section was started. Within 1-5 days, 195 of the 198 subjects (98.5\%) experienced return of adequate appetite suppression.

A consistent phenomenon occurred with Group 2 participants. When the amino acid precursor formula was added, each participant in Group 2 was able to retrospectively identify the exact day that appetite suppression was restored. This observation is consistent with a novel and sharply demarcated monoamine threshold. When monoamine levels were above the threshold, appetite suppression was observed. When monoamine levels were below the threshold, appetite suppression effects were not observed.

\section{Discussion}

The following definitions are put forth. Two basic types of nutritional deficiencies may occur: a "deficiency of nutrient

Table I Hamilton-D rating scale scores for Group I (depression, $\mathrm{n}=37$ )

\begin{tabular}{|c|c|c|c|c|c|c|}
\hline & $\mathbf{n}$ & $\begin{array}{l}\text { Mean Hamilton } \\
\text { score }\end{array}$ & $\begin{array}{l}\text { Hamilton score } \\
\text { ranges }\end{array}$ & $\begin{array}{l}\text { Standard deviation } \\
\text { of Hamilton Score }\end{array}$ & $\begin{array}{l}\text { Demographics } \\
\text { Female }\end{array}$ & $\begin{array}{l}\text { Demographics } \\
\text { Male }\end{array}$ \\
\hline & & & & & n (\%) & n (\%) \\
\hline & & & & & Age range (years) & Age range (years) \\
\hline & & & & & Mean age (years) & Mean age (years) \\
\hline & & & & & SD (years) & SD (years) \\
\hline \multirow[t]{4}{*}{ Pretreatment score $(>7)$} & 200 & 10 & $8-21$ & 3.39 & $\mathrm{n}=126(63.0 \%)$ & $\mathrm{n}=34(37.0 \%)$ \\
\hline & & & & & 18.1-74.2 & $25.4-81.6$ \\
\hline & & & & & 51.9 & 54.1 \\
\hline & & & & & 10.5 & 11.5 \\
\hline \multirow{4}{*}{$\begin{array}{l}\text { Scores two weeks after } \\
\text { starting drug }(\leq 7)\end{array}$} & 93 & 5 & $\mathrm{I}-7$ & 1.76 & $\mathrm{n}=60(64.5 \%)$ & $\mathrm{n}=33(35.5 \%)$ \\
\hline & & & & & $22.3-74.2$ & $25.4-74.5$ \\
\hline & & & & & 52.8 & 53.2 \\
\hline & & & & & 10.2 & 11.1 \\
\hline \multirow{4}{*}{$\begin{array}{l}\text { Score when effects } \\
\text { no longer observed }\end{array}$} & 37 & 12 & $7-23$ & 3.61 & $n=24(64.9 \%)$ & $\mathrm{n}=13(35.1 \%)$ \\
\hline & & & & & $23.4-68.2$ & $25.4-67.4$ \\
\hline & & & & & 50.7 & 51.1 \\
\hline & & & & & 9.1 & 9.8 \\
\hline \multirow{4}{*}{$\begin{array}{l}\text { Score one week after } \\
\text { starting amino acids }\end{array}$} & 36 & 4 & $0-7$ & 1.99 & $n=23(63.9 \%)$ & $n=13(36.1 \%)$ \\
\hline & & & & & $23.4-68.2$ & $25.4-67.4$ \\
\hline & & & & & 50.6 & 51.1 \\
\hline & & & & & 9.1 & 9.8 \\
\hline
\end{tabular}

Notes: Row I: Hamilton-D score prior to starting citalopram $20 \mathrm{mg}$ in the morning. Row 2: Hamilton-D score after relief of depression achieved on citalopram 20 mg per day. Row 3: Hamilton-D score when initial relief of symptoms after starting citalopram was no longer observed. Row 4: Hamilton-D score one week after the amino acid and cofactor formulation was started in combination with citalopram $20 \mathrm{mg}$. Abbreviation: SD, standard deviation. 
Table 2 Group 2 demographics of bariatric group by gender at start of treatment and at evaluation of quality of appetite suppression

\begin{tabular}{lll}
\hline & $\begin{array}{l}\text { Demographics } \\
\text { Female }\end{array}$ & $\begin{array}{l}\text { Demographics } \\
\text { Male }\end{array}$ \\
\cline { 2 - 3 } $\mathbf{n}(\%)$ & $\mathbf{n}(\%)$ \\
& $\begin{array}{l}\text { Mean age (years) } \\
\text { Age range (years) }\end{array}$ & $\begin{array}{l}\text { Mean age (years) } \\
\text { Age range (years) }\end{array}$ \\
& Age SD (years) & Age SD (years) \\
\hline 220 entering study & $173(78.6 \%)$ & $47(21.4 \%)$ \\
& 46.1 & 49.2 \\
& $18.1-69.6$ & $19.3-63.5$ \\
198 with adequate & 10.1 & 9.4 \\
appetite suppression & $157(79.3 \%)$ & $63(20.7 \%)$ \\
studied & 46.1 & 49.2 \\
& $18.8-68.2$ & $19.3-63.5$ \\
\hline
\end{tabular}

Abbreviation: SD, standard deviation.

intake" and a "relative nutritional deficiency." Relative nutritional deficiencies arise from changes in system status or from system needs that give rise to increased nutrient dosing needs that are beyond the limits of dietary modification.

\section{The theoretical model of monoamine depletion}

The central theory of this paper rests on the following foundation: reuptake inhibitors facilitate conditions that deplete monoamines, reuptake inhibitors will not function if monoamine depletion is significant enough, and when significant monoamine depletion occurs, the placebo effect and/or drug effect may no longer be observed.

The monoamines exist in one of two states. (1) The endogenous state is the normal day-to-day state found when no amino acid precursors are administered. In this state, monoamine levels are at or below the normal values of the reference range. (2) The competitive inhibition state is observed when significant amounts of serotonin and dopamine amino acid precursors are simultaneously administered. In this state, monoamine levels are higher than are normally found in the system. ${ }^{8,11,13-16}$

Table 3 Group I achieved relief of depression symptoms after starting citalopram then experienced return of symptoms leading to the listed observation. Group 2 achieved appetite suppression then experienced a lapse in the control of hunger leading to the listed observations

\begin{tabular}{lll}
\hline $\mathbf{n}$ & $\begin{array}{l}\text { Group I } \\
\mathbf{3 7}\end{array}$ & $\begin{array}{l}\text { Group 2 } \\
\mathbf{1 9 8}\end{array}$ \\
\hline $\begin{array}{l}\text { Mean (days to discontinuation } \\
\text { of effects after starting the drug[s]) }\end{array}$ & 164 & 22 \\
$\begin{array}{l}\text { Range (days to discontinuation } \\
\text { of effects after starting the drug) }\end{array}$ & $34-490$ & $4-48$ \\
\begin{tabular}{l} 
Standard deviation \\
\hline
\end{tabular} & 107.5 & 9.1 \\
\hline
\end{tabular}

Table 4 Group I subjects achieved relief of depression symptoms after starting citalopram and then experienced a return of symptoms. The amino acid precursor formula was then administered in combination with citalopram, and the listed study parameters were observed. Group 2 subjects achieved appetite suppression after starting citalopram and phentermine in combination, then experienced a return of appetite. The amino acid precursor formula was then administered in combination with citalopram and phentermine and the listed parameters were observed

\begin{tabular}{lll}
\hline $\mathbf{n}$ & Group I & Group 2 \\
& $\mathbf{3 7}$ & $\mathbf{1 9 8}$ \\
\hline Effects restored (n, [\%]) & $36(97.3 \%)$ & $195(98.5 \%)$ \\
Mean time to restore effects (days) & 1.6 days & 1.9 days \\
Range (days) & $1-3$ & $1-5$ \\
Standard deviation & 0.26 days & 0.39 days \\
\hline
\end{tabular}

The mechanism of action for reuptake inhibitors is only theoretical; objective measurements do not exist. A debate exists over drug tachyphylaxis versus placebo relapse when there is a return of symptoms of depression or ADHD after being controlled at the start of the drug. Relapse supporters claim their argument makes room for recurrence of symptoms in the presence of a large placebo effect combined with a small drug effect. ${ }^{9} 10$

It is postulated that the following novel reuptake inhibitor monoamine depletion theory is a viable explanation, especially in light of the amino acid observations summarized in Tables 1, 3, and 4 plus the differentiation of synaptic and postsynaptic electrical dysfunction. The reuptake inhibitor monoamine depletion theory states that reuptake inhibitors deplete the monoamines serotonin, dopamine, norepinephrine, and epinephrine in all subjects not ingesting adequate amounts of balanced nutrients; when depletion is significant enough, a point is reached where the effects of the drug and/ or the placebo effect are no longer observed.

The uniform and consistent response observed with low-dose amino acid dosing values, which uniformly places all subjects in the lower end of the competitive inhibition state, supports the reuptake inhibitor monoamine depletion theory.

The reported numbers (n) in rows 3 and 4 of Table 1 are higher than expected based on expected drug response alone, meaning that these subjects are a mix of placebo responders and drug responders. Note that $>97 \%$ of this group responded to the administration of amino acid precursors. It is therefore concluded that this is a synaptic phenomenon related to monoamine depletion by reuptake inhibitors, which is the primary cause of placebo relapse and drug tachyphylaxis. 
It is proposed that monoamine depletion is the correct description of the event that occurs when drug or placebo effects observed after the start of a reuptake inhibitor are no longer present in the endogenous state. With monoamine depletion, the synaptic monoamine levels decrease due to a relative nutritional deficiency that is beyond the capabilities of dietary modification to correct. The effects of placebo and/or drug efficacy will not be available if there are not enough monoamines in the system. With significant monoamine depletion by reuptake inhibitors, there may be a return of the original disease symptoms or new onset of disease symptoms.

\section{Relapse versus tachyphylaxis}

Some argue that, with reuptake inhibitor treatment of depression and ADHD, the placebo effect is the dominant force facilitating the clinical response; therefore, the appropriate term when symptoms return after a reuptake inhibitor response is observed is "relapse," rather than drug tachyphylaxis. ${ }^{9,10}$ The placebo effect in depression ranges from $30 \%$ to $45 \%$, and drug efficacy over placebo ranges from $7 \%$ to $13 \%{ }^{7}$ Double-blind, placebo-controlled depression studies reveal that the efficacy of placebo is three to six times greater than that of reuptake inhibitors. In these studies, the drug effect is so small that $87 \%-93 \%$ treated with a reuptake inhibitor can expect relief of symptoms no greater than that provided by placebo. ${ }^{7}$

Double-blind, placebo-controlled ADHD studies of atomoxetine indicate placebo efficacy in the range of $28 \%-40 \%$, with drug efficacy $12 \%-26 \%$ greater than placebo. Studies support the conclusion that $74 \%-88 \%$ of ADHD patients treated with atomoxetine can expect relief of symptoms no greater than that provided by placebo. ${ }^{8}$

\section{Monoamine depletion}

The primary theory expounded by this paper is that when symptomatic relief related to a drug or placebo wanes, it is primarily due to drug-induced monoamine depletion. Monoamine depletion studies done in conjunction with amino acid precursor utilization have demonstrated that a decrease in monoamine concentrations is associated with the waning or outright discontinuation of the drug-induced effects. ${ }^{18,19}$

Serotonin and dopamine are synthesized from the amino acid precursors 5-hydroxytryptophan (5-HTP) and L-3,4dihydroxyphenylalanine (L-dopa), respectively. L-dopa is synthesized from L-tyrosine and 5-HTP is synthesized from L-tryptophan. Dopamine is the precursor of norepinephrine, which, in turn, is the precursor of epinephrine. . $^{7,11-16,20-22}$
Monoamines do not cross the blood-brain barrier. When monoamine depletion of the CNS occurs, the only way to address this relative nutritional deficiency and increase the total number of monoamine molecules in the CNS is through nutritional means, with the simultaneous administration of properly balanced serotonin and dopamine amino acid precursors with cofactors. These precursors cross the blood-brain barrier and are then synthesized, freely or with biochemical feedback regulation depending on the amino acid, into new monoamines, which, when levels are high enough, restore the efficacy of the drug or placebo effect. , $^{8,11-16,21}$

\section{Depletion of platelet monoamines: peripheral evidence}

Platelets contain $90 \%$ of the releasable serotonin stores. Reuptake inhibitor studies demonstrate that $90 \%$ of platelet serotonin is depleted in about 3 weeks. Over $80 \%$ of the total releasable serotonin is depleted within 3 weeks after starting reuptake inhibitors. The mechanism of platelet depletion is attributed to blocking reuptake transport of serotonin into platelets while allowing for transport out of the platelets. Once outside the platelets, the serotonin is exposed to the monoamine oxidase enzymes that affect metabolism at a higher rate leading to depletion. This is the same mechanism of action observed with monoamine transport in and out of the presynaptic neurons of the CNS, as illustrated in Figures $1-3 .^{23-30}$

\section{Depletion in CNS}

Do reuptake inhibitors facilitate CNS monoamine depletion? In excess of $80 \%$ of the releasable stores of serotonin are depleted after 3 weeks of reuptake inhibitor treatment.

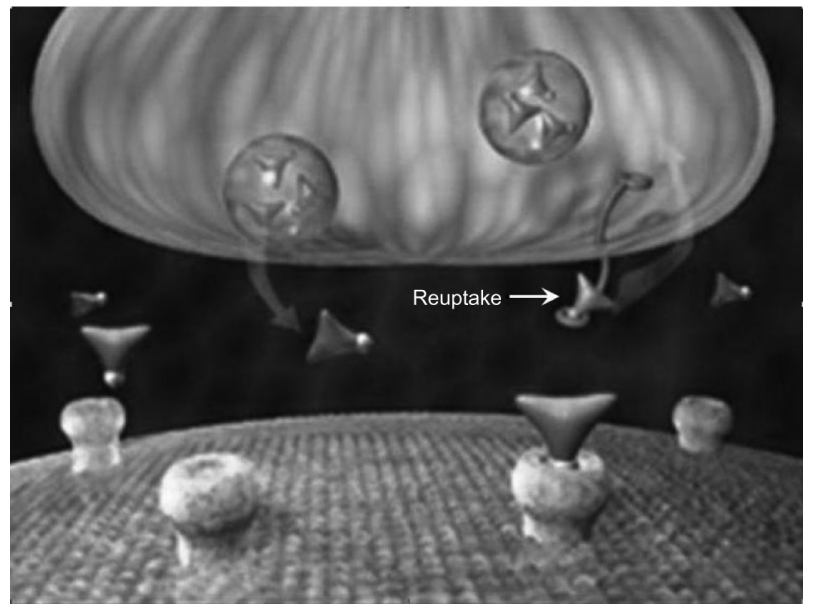

Figure I Inadequate levels of neurotransmitters in the synapse are associated with compromised electrical flow in the postsynaptic neurons, leading to suboptimal regulation of function and/or development of symptoms. ${ }^{34}$ 


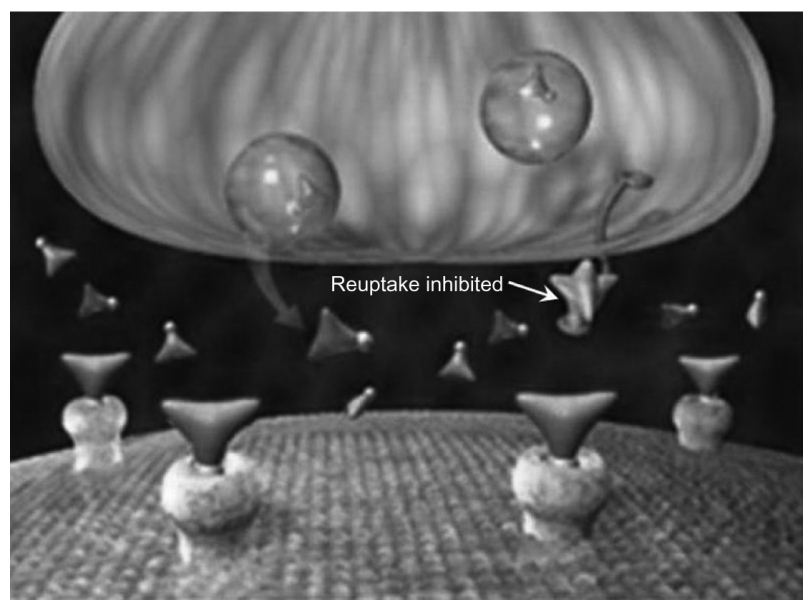

Figure 2 With administration of reuptake inhibitors, blockage of monoamine transport back into the presynaptic neurons leads to a net redistribution of neurotransmitter molecules from the presynaptic neuron to the synapse. Increased levels of synaptic monoamines lead to increased flow of electricity which causes adequate regulation of function and/or relief of symptoms. ${ }^{34}$

There is disagreement over the depletion of monoamines by reuptake inhibitors in the CNS. Supporters of reuptake inhibitors assert that there is no evidence of CNS monoamine depletion by these drugs. Those in opposition, including the National Institute on Drug Abuse, claim that reuptake inhibitors deplete CNS monoamines. ${ }^{23-30}$

One paper bridges the gap, its authors initially recognizing articles claiming reuptake inhibitors do not deplete monoamines in the CNS. The article then identifies pathological and morphological changes that occur with drug depletion and goes on to explain that these same changes are seen

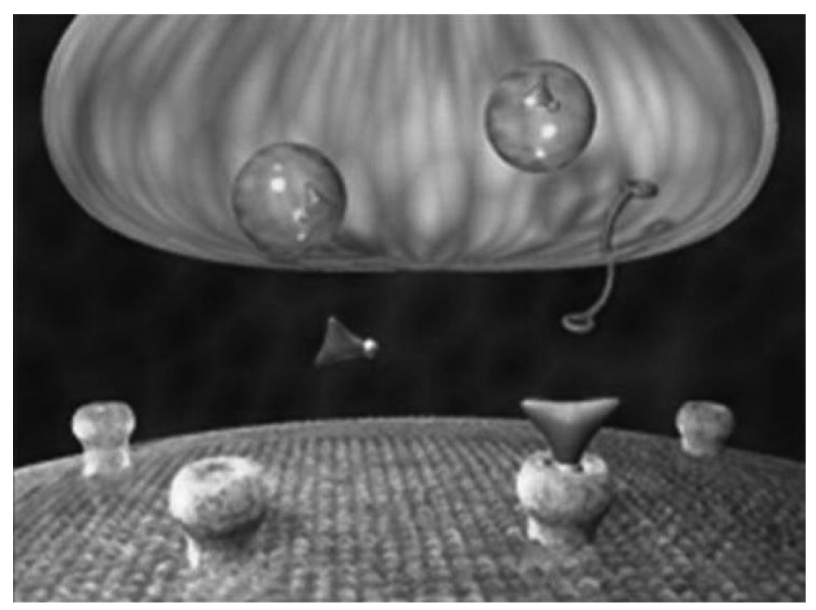

Figure 3 When the monoamines are in the vesicles of the presynaptic neuron they are not exposed to the enzymes that catalyze metabolism (monoamine oxidase and catechol-0-methyl transferase). They are safe from metabolism. When they relocate outside the vesicles presynaptic neuron, they are exposed at a greater frequency to these enzymes. Reuptake inhibitors create a mass migration of monoamines causing increased metabolic enzyme activity and metabolism of monoamines. This leads to monoamine depletion if significant amounts of balanced serotonin and dopamine precursors are not coadministered with the reuptake inhibitor. ${ }^{34}$ with reuptake inhibitor administration. These morphological changes are found with all reuptake inhibitors reviewed. A spectrum of depletion is concluded. ${ }^{31}$

\section{Differentiating synaptic and postsynaptic dysfunction}

While the focus of monoamine reuptake inhibitor depletion is on synaptic monoamine levels, there are other causes of electrical dysfunction, such as receptor desensitization and receptor down regulation. While these may be valid topics, they do not apply here. The phenomenon observed here is clearly electrical dysfunction of synaptic origin, whereas receptor desensitization, receptor down regulation, bundle damage, and so forth, are all postsynaptic processes linked to the postsynaptic neurons. As discussed in the authors' previous work, there are unique observations that define synaptic electrical dysfunction versus postsynaptic-driven electrical dysfunction. Considerations are as follows. Correcting monoamine depletion-associated synaptic electrical dysfunction in the endogenous state involves addressing the problem nutritionally to increase monoamine concentrations from low to normal. ${ }^{7,8,11-16,20-22}$ Correcting dysfunction associated with postsynaptic structures requires nutritionally establishing monoamine levels in the competitive inhibition state, where monoamine levels are higher than those found in the endogenous (normal) state. , $8,11-16,20-22$ Differentiation between synaptic and postsynaptic electrical dysfunction is possible by observing the clinical response to group administration of nutrients (amino acid precursors with cofactors), shown in Table 5. . $, 8,11-16,20-22^{-10}$

When dysfunction is due to low or inadequate synaptic monoamine levels associated with depletion, returning monoamine levels to the normal reference range of the population in the endogenous state will correct the problem. ${ }^{7,8,11-16,20-22}$ In Group 1 and Group 2, over 97\% of subjects who experienced waning of initial drug effects were suffering from monoamine electrical dysfunction secondary to developing a relative nutritional dysfunction. These subjects were placed on the lowest (starting) amino acid dosing value required to induce the competitive inhibition state leading to a positive and uniform response. As discussed more thoroughly below, when synaptic monoamine electrical dysfunction is present, returning monoamine levels to the normal range for the population or immediately above normal restores the initial effects observed with administration of the drug. ${ }^{7,8,11-16,20-22}$

When the electrical dysfunction is due to postsynaptic neuron structural impairment, the serotonin and dopamine amino acid precursor dosing values required to fully 
Table 5 Observed differences between synaptic and postsynaptic electrical dysfunction

\begin{tabular}{|c|c|c|}
\hline & $\begin{array}{l}\text { Synaptic } \\
\text { dysfunction }\end{array}$ & $\begin{array}{l}\text { Postsynaptic } \\
\text { dysfunction }\end{array}$ \\
\hline $\begin{array}{l}\text { Electrical dysfunction } \\
\text { is corrected with monoamines } \\
\text { in which state? }\end{array}$ & $\begin{array}{l}\text { Endogenous } \\
\text { state }\end{array}$ & $\begin{array}{l}\text { Competitive } \\
\text { inhibition state }\end{array}$ \\
\hline $\begin{array}{l}\text { Returning monoamines } \\
\text { to normal levels }\end{array}$ & $\begin{array}{l}\text { Will restore } \\
\text { function }\end{array}$ & $\begin{array}{l}\text { Will not } \\
\text { restore function }\end{array}$ \\
\hline $\begin{array}{l}\text { Uniform response to a } \\
\text { low-dose competitive inhibition } \\
\text { amino acid dosing value }\end{array}$ & Yes & No \\
\hline $\begin{array}{l}\text { Individualized amino acid } \\
\text { dosing value needed }\end{array}$ & No & Yes \\
\hline $\begin{array}{l}\text { Requires adjusting amino acid } \\
\text { dosing values for } \\
\text { optimal group results }\end{array}$ & No & Yes \\
\hline $\begin{array}{l}\text { Need to obtain organic } \\
\text { cation transporter functional } \\
\text { status determination } \\
\text { for optimal results }\end{array}$ & No & Yes \\
\hline
\end{tabular}

compensate for the dysfunction are not uniform and are highly individualized. ${ }^{7,8,11-16,20-22}$

As the authors have previously discussed, the following considerations exist while documenting the novel effects of nutritional dosing value alterations on organic cation transporter (OCT) function status in the competitive inhibition state. The serotonin and dopamine precursor dosing values needed to compensate for postsynaptic monoamine-associated electrical dysfunction in the competitive inhibition state range from very low to very high. When optimal amino acid precursor dopamine values in the competitive inhibition state are achieved, as evidenced by properly balanced OCT serotonin and dopamine transport, the serotonin amino acid dosing value is independent of the dopamine amino acid dosing value. In addition, if OCT functional status interpretation considerations are not affected, the dosing values of serotonin and dopamine amino acid precursors needed to effectively optimize and restore postsynaptic monoamine-related electrical function have been demonstrated to be random relative to serotonin and dopamine assay levels. 7,8,11-16,20-22

In the case of reuptake inhibitor placebo relapse and/or reuptake inhibitor tachyphylaxis, the amino acid dosing values required to correct the relative nutritional deficiency are relatively low, uniform, and constant. This is consistent with synaptic monoamine electrical dysfunction in endogenous state. It is not consistent with the highly individualized group-dosing value needs observed in the competitive inhibition state, which is linked to postsynaptic monoamine electrical dysfunction (see Table 5). ${ }^{7,8,11-16,20-22}$

\section{Neurotransmitter depletion by reuptake inhibitors}

It is known that the reuptake inhibitor methamphetamine depletes dopamine, ${ }^{32}$ which facilitates the neurotoxicity. ${ }^{8}$ SSRIs are known to decrease serotonin synthesis. ${ }^{33}$ The nonspecific reuptake inhibitor amitriptyline (a tricyclic antidepressant) is known to deplete norepinephrine. ${ }^{34}$ The National Institute on Drug Abuse has posted figures (Figures 1-3) on its website, which are in the public domain. These figures illustrate how reuptake inhibitors deplete monoamines. ${ }^{35}$

\section{Other depletion-related problems}

Monoamine depletion may explain other problems associated with reuptake inhibitors. The US Food and Drug Administration requires that reuptake inhibitors display a black box warning regarding the risk of suicidal ideation while taking these drugs. ${ }^{4,5}$ It is postulated that this increased suicide risk may be associated with monoamine depletion by reuptake inhibitors.

Reuptake inhibitor discontinuation syndrome is an exacerbation of symptoms or new onset of symptoms that occurs when attempts are made to stop a reuptake inhibitor. The patients typically, do not like the way they feel when attempts to stop the drug are made; consequently they are trapped into taking a drug that provides little relief of symptoms because they feel worse without the drug. ${ }^{37}$ It is postulated that reuptake inhibitor-induced monoamine depletion plays a role in this phenomenon.

Customarily, when the clinical effect of a reuptake inhibitor stops, the response is to increase the daily dosing value of the drug, start a second reuptake inhibitor, or stop the first drug then substitute a second drug. It is postulated that all of these actions further facilitate monoamine depletion.

\section{General observations}

It is postulated that if the reuptake inhibitor drug was introduced into an environment in which synaptic monoamine homeostasis always existed, with no postsynaptic issues arising, the drug would theoretically continue to function indefinitely. However, this is not the case. It is well known that these drugs, in the endogenous state, are associated with return of symptoms, discontinuation syndrome, placebo relapse, drug tachyphylaxis, suicidal ideation, reuptake inhibitor discontinuation syndrome, induced relative nutritional deficiency, and a number of other problems. Reuptake inhibitor monoamine depletion theory is the only model that unifies and explains the phenomena described in this paper 
when the nutritional responses of Group 1 and Group 2 are considered.

Reuptake inhibitors are a drug class that offer only $7 \%-13 \%$ of patients relief of depression symptoms that is greater than that provided by placebo. ${ }^{7}$ They make the disease cause worse by depleting the centrally acting monoamine neurotransmitters in all patients who do not ingest adequate amounts of serotonin and dopamine amino acid precursors, which leads to a relative nutritional deficiency. They also expose $100 \%$ of patients to drug side effects and the economic costs of the drugs.

Worldwide annual sales of antidepressants coming off patent between 2011 and 2016 is placed in excess of US\$255 billion. ${ }^{37}$ If $87 \%$ of patients taking these drugs had no hope of achieving relief of depression symptoms greater than that provided by placebo, this would mean that US\$221.9 billion is being spent annually for treatment that is no more effective than a sugar pill. This number increases when the cost of drugs already off patent are included.

The Internet is replete with claims that 5-HTP should not be administered with reuptake inhibitors due to concerns of serotonin syndrome. The authors firmly assert that this is not correct. There are no reported cases of serotonin syndrome resulting from concurrent use of 5-HTP with reuptake inhibitors in the literature. Since 1997, the authors have amassed over 2 million patient-days of treatment experience using 5-HTP with reuptake inhibitors from over 1000 medical clinics, with not one case of serotonin syndrome documented.

\section{Conclusion}

SSRIs used in the treatment of depression and ADHD are associated with low efficacy and high placebo response. This leads to controversy in defining the cause for the discontinuation of symptomatic relief observed after starting a reuptake inhibitor. Prior to this paper, the question was, "When depression symptoms return, is it due to drug tachyphylaxis or a placebo relapse?" This paper puts forth the unified concept of the reuptake inhibitor monoamine depletion theory.

Relative nutritional deficiency can exist when dietary intake is normal and changes to the system occur that cannot be met through dietary modification alone. Increased metabolism and inadequate synthesis of monoamines create an environment where the relative nutritional deficiency associated with reuptake inhibitor treatment evolves. When this happens, administration of serotonin and dopamine amino acid precursors is the only course available to compensate for CNS monoamine depletion by reuptake inhibitors.

The ability of reuptake inhibitors to induce a relative nutritional deficiency leading secondarily to depletion of monoamines has been overlooked and is of serious concern. When monoamine depletion is extensive enough, placebo relapse occurs, drug tachyphylaxis occurs, symptoms of disease return, new onset of disease symptoms may occur, increased incidence of suicidal ideation may be facilitated, and reuptake inhibitor discontinuation syndrome may be observed, regardless of the initial cause of symptomatic relief (placebo effect versus drug effect).

Reuptake inhibitors do not increase the total number of monoamines in the CNS. Their mechanism of action facilitates redistribution of monoamines from one place to another, which, in turn, sets up conditions that favor depletion of monoamines if proper levels of nutrients are not administered.

Physicians currently prescribe reuptake inhibitor drugs that are only $7 \%-13 \%$ more effective than placebo in treating depression $^{7}$ and only $12 \%-26 \%$ more effective than placebo in treating ADHD. ${ }^{8}$ Reuptake inhibitors are known to further deplete the very monoamines whose inadequate synaptic levels are implicated in the etiology of numerous diseases and conditions. This makes the cause of the disease (ie, inadequate monoamine levels) worse. Monoamine depletion is a relative nutritional deficiency that cannot be managed adequately by dietary modification.

In the treatment of depression, $87 \%-93 \%$ of patients taking these drugs cannot expect relief of symptoms that is greater than that provided by placebo. ${ }^{7}$ In the treatment of ADHD, $74 \%-88 \%$ of patients cannot expect relief of symptoms greater than that provided by placebo. ${ }^{8}$ However, $100 \%$ of patients are subjected to the side effects, the cost of the drugs, development of a relative nutritional deficiency, and depletion of monoamines by reuptake inhibitors if simultaneous administration of properly balanced serotonin and dopamine amino acid precursors does not occur.

Reuptake inhibitors are the only class of drugs that the authors are aware of that make the cause of the disease (inadequate levels of monoamines) that is being treated worse. With experience comes insight: the manufacturer of citalopram reported that one of the authors of this article was the largest private practice prescriber of this drug in 1999, the first full year after the drug became available in the USA. This paper attempts to raise the level of awareness, understanding, stimulate further studies, and facilitate dialog regarding monoamine depletion by reuptake inhibitors.

\section{Disclosure}

MH discloses ownership of NeuroResearch Clinics Inc, Cape Coral, FL. TU discloses laboratory directorship of DBS Labs, 
Duluth, MN. AS declares no conflicts of interest in relation to this paper.

\section{References}

1. Frank R, Glied S. Better but Now Well: Mental Health Policy in the United States since 1950. Baltimore, MD: Johns Hopkins University Press; 2006.

2. Mantzoros C. Nutrition and Metabolism: Underlying Mechanisms and Clinical Consequences. Totowa, NJ: Humana Press; 2009.

3. Dextroamphetamine and amphetamine (CII) prescribing information. Available from: http:/www.accessdata.fda.gov/drugsatfda_docs/ label/2007/011522s040 lbl.pdf. Accessed July 30, 2011.

4. Fluvoxetine prescribing information. Available from: http://www. luvoxcr.com/LUVOX-CR-PI.pdf. Accessed July 30, 2011.

5. Bupropion prescribing information. Available from: http://us.gsk.com/ products/assets/us_zyban.pdf. Accessed July 30, 2011.

6. Merriam-Webster online dictionary http://www.merriam-webster.com/ medical $/$ tachyphylaxis? show $=0 \& \mathrm{t}=1312033095$. Accessed July 30, 2011.

7. Hinz M. Depression. In: Kohlstadt I, editor. Food and Nutrients in Disease Management. Boca Raton, FL: CRC Press; 2009.

8. Hinz M, Stein A, Uncini T. Treatment of attention deficit hyperactivity disorder with monoamine amino acid precursors and organic cation transporter assay interpretation. Neuropsychiatr Dis Treat. 2011;7:31-38.

9. McGrath P, Stewart J, Quitkin F. Predictors of relapse in a prospective study of fluoxetine treatment of major depression. Am J Psychiatry. 2006;163:1542-1548.

10. Michelson D, Buitelaar J, Danckaerts M. Relapse prevention in pediatric patients with ADHD treated with atomoxetine: a randomized, double blind, placebo controlled study. J Am Acad Child Adolesc Psychiatry. 2004;43:896-904.

11. Hinz M, Stein A, Uncini T. The dual-gate lumen model of renal monoamine transport Neuropsychiatr Dis Treat. 2010;6:387-392.

12. Hinz M, Stein A, Trachte G, Uncini T. Neurotransmitter testing of the urine: A comprehensive analysis. Open Access Journal of Urology. 2010;2:177-183.

13. Hinz M, Stein A, Uncini T. Urinary neurotransmitter testing: considerations of spot baseline norepinephrine and epinephrine. Open Access Journal of Urology. 2011;3:19-24.

14. Hinz M, Stein A, Uncini T. Amino acid management of Parkinson's disease: A case study. Int J Gen Med. 2011;4:1-10.

15. Hinz M, Stein A, Uncini T. Validity of urinary monoamine assay sales under the "spot baseline urinary neurotransmitter testing marketing model". Int J Nephrol Renovasc Dis. 2011;4:101-113.

16. Hinz M, Stein A, Uncini T. APRESS: apical regulatory super system, serotonin, and dopamine interaction. Neuropsychiatr Dis Treat 2011;7:457-463.

17. Diagnostic and Statistical Manual of Mental Disorders, Fourth Edition, 1994 (American Psychiatric Association) p. 372

18. Delgado P, Miller H, Salomon R, et al. Tryptophan-depletion challenge in depressed patients treated with desipramine or fluoxetine: implications for the role of serotonin in the mechanism of antidepressant action. Biol Psychiatry. 1999;46:212-220.

19. Page M, Detke M, Dalvi A, et al. Serotonergic mediation of the effects of fluoxetine, but not desipramine, in the rat forced swimming test. Psychopharmacology. 1999;147:162-167.

Drug, Healthcare and Patient Safety

\section{Publish your work in this journal}

Drug, Healthcare and Patient Safety is an international, peer-reviewed open-access journal exploring patient safety issues in the healthcare continuum from diagnostic and screening interventions through to treatment, drug therapy and surgery. The journal is characterized by the rapid reporting of reviews, original research, clinical, epidemiological and
20. Trachte G, Uncini T, Hinz M. Both stimulatory and inhibitory effects of dietary 5-hydroxytryptophan and tyrosine are found on urinary excretion of serotonin and dopamine in a large human population. Neuropsychiatr Dis Treat. 2009;5:227-235.

21. Stein A, Hinz M, Uncini T. Amino acid responsive Crohn's disease, a case study. Clin Exp Gastroenterol. 2010:3:171-177.

22. Hinz M, Stein A, Uncini T. A pilot study differentiating recurrent major depression from bipolar disorder cycling on the depressive pole. $\mathrm{Neu}$ ropsychiatr Dis Treat. 2010;6:741-747.

23. Alvarez J, Sanceaume M, Advenier C, et al. Differential changes in brain and platelet 5-HT concentrations after steady-state achievement and repeated administration of antidepressant drugs in mice. Eur Neuropsychopharmacol. 1999;10:31-36.

24. Dalton S, Johansen C, Mellemkjar L, et al. Use of selective serotonin reuptake inhibitors and risk of upper gastrointestinal tract bleeding. Arch Intern Med. 2003;163:59-64.

25. Wagner A, Montero D, Martensson B, et al. Effects of fluoxetine treatment of platelet 3H-imipramine binding, 5-HT uptake and 5-HT content in major depressive disorder. J Affect Disord. 1990;20:101-113.

26. Yuan Y, Tsoi K, Hunt R. Selective serotonin reuptake inhibitors and risk of upper GI bleeding: Confusion or confounding? Am J Med. 2006;119:719-727.

27. Meier C, Schlienger R, Jick H. Use of selective serotonin reuptake inhibitors and risk of developing first-time acute myocardial infarction. Br J Clin Pharmacol. 2001;52:179-184.

28. Fuller R, Wong D. Serotonin uptake and serotonin uptake inhibition. Ann NY Acad Sci. 1990;600:68-78.

29. de Abajo FJ, Jick H, Derby L, Jick S, Schmitz S. Intracranial haemorrhage and use of selective serotonin reuptake inhibitors. $\mathrm{Br} J \mathrm{Clin}$ Pharmacol. 2000;50:43-47.

30. Layton D, Clark D, Pearce D, Shakir SA. Is there an association between reuptake inhibitors and the risk of abnormal bleeding? Eur J Clin Pharmacol. 2001;57:167-176.

31. Kalia M, O'Callaghan J, Miller D, et al. Comparative study of fluoxetine, sibutramine, sertraline and dexfenfluramine on the morphology of serotonergic nerve terminals using serotonin immunohistochemistry. Brain Res. 2000;858:92-105.

32. Cooney C, Wise C, Poirier LA, Ali SF. Methamphetamine treatment affects blood and liver $S$-adenosylmethionine (SAM) in mice: correlation with dopamine depletion in the striatum. Ann NY Acad Sci. 1998;844:191-200.

33. Stenfors C, Yu H, Ross S. Pharmacological characterisation of the decrease in 5-HT synthesis in the mouse brain evoked by the selective serotonin re-uptake inhibitor citalopram. Arch Pharmacol. 2001;363:222-232.

34. Galun E, Flugelman M, Glickson M, et al. Failure of long-term digitalization to prevent rapid ventricular response in patients with paroxysmal atrial fibrillation. Chest. 1991;99:1038-1040.

35. National Institute of Drug Abuse. The neurobiology of ecstasy. Slides 9-11. Available from: http://www.nida.nih.gov/pubs/teaching/ Teaching4/Teaching.html. Accessed July 29, 2011.

36. Black K, Shea C, Dursun S. Selective serotonin reuptake inhibitor discontinuation syndrome: proposed diagnostic criteria. J Psychiatry Neurosci. 2000;25:255-261.

37. Forbes. Available from: http://www.forbes.com/feeds/ap/2011/07/25/ general-health-care-us-generics-bonanza_8582330.html. Accessed July $31,2011$.

\section{Dovepress}

post-marketing surveillance studies, risk management, health literacy and educational programs across all areas of healthcare delivery. The manuscript management system is completely online and includes a very quick and fair peer-review system. Visit http://www.dovepress.com/ testimonials.php to read real quotes from published authors. 